\title{
Absence of Transient Receptor Potential Vanilloid-1 Accelerates Stress-Induced Axonopathy in the Optic Projection
}

\author{
Nicholas J. Ward, Karen W. Ho, Wendi S. Lambert, Carl Weitlauf, and David J. Calkins \\ Vanderbilt Eye Institute, Vanderbilt University Medical Center, Nashville, Tennessee 37232-0654
}

How neurons respond to stress in degenerative disease is of fundamental importance for identifying mechanisms of progression and new therapeutic targets. Members of the transient receptor potential (TRP) family of cation-selective ion channels are candidates for mediating stress signals, since different subunits transduce a variety of stimuli relevant in both normal and pathogenic physiology. We addressed this possibility for the TRP vanilloid-1 (TRPV1) subunit by comparing how the optic projection of $\operatorname{Trpv1} 1^{-1-}$ mice and age-matched C57 controls responds to stress from elevated ocular pressure, the critical stressor in the most common optic neuropathy, glaucoma. Over a 5 week period of elevated pressure induced by microbead occlusion of ocular fluid, Trpv1 ${ }^{-1-}$ accelerated both degradation of axonal transport from retinal ganglion cells to the superior colliculus and degeneration of the axons themselves in the optic nerve. Ganglion cell body loss, which is normally later in progression, occurred in nasal sectors of Trpv1 ${ }^{-1-}$ but not C57 retina. Pharmacological antagonism of TRPV1 in rats similarly accelerated ganglion cell axonopathy. Elevated ocular pressure resulted in differences in spontaneous firing rate and action potential threshold current in Trpv1 ${ }^{-1-}$ ganglion cells compared with C57. In the absence of elevated pressure, ganglion cells in the two strains had similar firing patterns. Based on these data, we propose that TRPV1 may help neurons respond to disease-relevant stressors by enhancing activity necessary for axonal signaling.

Key words: glaucoma; microbead glaucoma; optic nerve; retinal ganglion cell; superior colliculus; TRPV1

\section{Introduction}

Onset and progression of neurodegeneration in disease and injury involves complex interlacing of both protective and destructive intracellular and extracellular signals. How such signals arise in response to relevant stressors is critical for understanding disease progression and for identifying early molecular targets for therapeutic intervention. The transient receptor potential (TRP) family of cation-selective ion channels mediates a variety of neuronal responses to both physiologic and pathogenic stimuli (Lin and Corey, 2005; Ho et al., 2012; Vennekens et al., 2012). The diversity of different TRP subunits arises in part from the broad spectrum of ligand-based, membrane-

Received Sept. 23, 2013; revised Jan. 14, 2014; accepted Jan. 16, 2014.

Author contributions: N.J.W., C.W., and D.J.C. designed research; N.J.W., K.W.H., W.S.L., and C.W. performed research; N.J.W., W.S.L., C.W., and D.J.C. analyzed data; N.J.W., C.W., and D.J.C. wrote the paper.

This research was supported by National Institutes of Health (NIH) Grants EY017427 (D.J.C.) and 5T32EY007135-18 (N.J.W.), Senior Scientific Investigator and Departmental Unrestricted Awards from Research to Prevent Blindness, Inc. (D.J.C.), and the Melza M. and Frank Theodore Barr Foundation through the Glaucoma Research Foundation (D.J.C.). Imaging was supported through the Vanderbilt University Medical Center Cell Imaging Shared Resource core facility [Clinical and Translational Science Awards Grant UL1 RR024975 from the National Center for Research Resources (NCRR) at NIH], the Vanderbilt Vision Research Center (Grant P30EY008126), the NCRR (Grant UL1 RR024975-01), and the National Center for Advancing Translational Sciences (Grant 2 UL1 TR000445-06). We thank Brian J. Carlson, Samuel D. Crish, Tracey S. Hong, and Tina T. Tian for their assistance with the project.

The authors declare no competing financial interests.

Correspondence should be addressed to David J. Calkins, Department of Ophthalmology and Visual Sciences, The Vanderbilt Eye Institute, Vanderbilt University Medical Center, 11425 Medical Research Building IV, Nashville, TN 37232-0654. E-mail: david.j.calkins@vanderbilt.edu.

DOI:10.1523/JNEUROSCI.4089-13.2014

Copyright $\odot 2014$ the authors $\quad 0270-6474 / 14 / 343161-10 \$ 15.00 / 0$ bound, and biophysical mechanisms through which they are activated. The capsaicin-sensitive TRP vanilloid-1 (TRPV1) subunit exemplifies this diversity, contributing to tactile sensitivity, diabetic sensory neuropathy, pressure-induced pain, injury monitoring, and visceral distension (Mutai and Heller, 2003; Hwang et al., 2004; Rong et al., 2004; Scotland et al., 2004; Jones et al., 2005; Ma et al., 2005; Liedtke, 2006; Plant et al., 2006; Daly et al., 2007; Pingle et al., 2007). Like other TRP subunits, TRPV1 activation is associated with a robust $\mathrm{Ca}^{2+}$ conductance that supports many $\mathrm{Ca}^{2+}$-dependent intracellular cascades linked to both normal signaling and stress-related processes (Agopyan et al., 2004; Aarts and Tymianski, 2005; Reilly et al., 2005; Kim et al., 2006; Miller, 2006).

In the optic projection, retinal ganglion cells (RGCs) and their axons express TRPV1 and other TRP channels, which upon activation increase intracellular $\mathrm{Ca}^{2+}$ and modulate survival of RGCs challenged by different disease-relevant stressors such as ischemic insult and pressure (Nucci et al., 2007; Maione et al., 2009; Sappington et al., 2009; Wang et al., 2010; Ryskamp et al., 2011; Leonelli et al., 2013). TRPV1 also contributes to retinal glial cell signaling and may modulate RGC survival indirectly through inflammatory cytokine pathways (Sappington and Calkins, 2008). These results all have a bearing on RGC survival in individuals with glaucoma, the most common optic neuropathy and leading cause of irreversible blindness worldwide (Quigley and Broman, 2006). Glaucoma involves sensitivity to intraocular pressure (IOP), a potent stressor that induces early 
RGC axonal dysfunction with subsequent optic nerve degeneration and later loss of RGC bodies in the retina (Calkins, 2012; Howell et al., 2012). We have presented evidence that TRPV1 in RGCs directly contributes to transducing stress typically associated with glaucoma (Sappington et al., 2009). In this, our follow-up study, we tested how genetic knockout of $\operatorname{Tr} p v 1$ $(-/-)$ influences the progression of RGC degeneration with exposure to elevated IOP in an inducible model. We found that $\operatorname{Trp} v 1^{-1-}$ accelerated RGC degeneration in vivo, as did systemic treatment with a subunit-specific antagonist. $\operatorname{Tr} p v 1^{-1-}$ also altered physiological responses to elevated ocular pressure when compared with C57BL/6 (C57) mice. We propose that TRPV1 may help neurons survive disease-relevant stressors by boosting activity necessary for axonal signaling.

\section{Materials and Methods}

Animals. The Vanderbilt University Medical Center Institutional Animal Care and Use Committee approved all experimental procedures. Adult (4-month-old) male $\operatorname{Tr} p v 1^{-1-}$ (B6.129X1-Trpv1 $1^{\text {tm IJul } / J)}$ mice were obtained from Jackson Laboratories and genotyped before experimentation to confirm the transgene, following protocols provided by Jackson Laboratories. These mice have a targeted mutation caused by a disrupted exon encoding part of the fifth and all of the sixth transmembrane pore regions; age-matched C57 mice, which we obtained from Charles River Laboratories are the appropriate control mice (Caterina et al., 2000; Ciura and Bourque, 2006; Treesukosol et al., 2007). Mice were maintained in a $12 \mathrm{~h}$ light/dark cycle with standard rodent chow available ad libitum.

We measured IOP bilaterally in anesthetized (2.5\% isoflurane) mice using a TonoPen XL rebound tonometer (Medtronic Solan) as previously described (Inman et al., 2006; Sappington et al., 2010). An IOP measurement was determined as the mean of at least 20 readings. To avoid corneal irritation, hydrating eye drops were administered to each eye at the completion of IOP measurements. Before induced elevation, we monitored IOP for 2-3 d; the measurements over this period for each eye were averaged to obtain a baseline value (day 0 ). We elevated IOP in cohorts of C57 and Trpv1 ${ }^{-1-}$ mice using microbead occlusion of aqueous outflow as described previously (Crish et al., 2010; Sappington et al., 2010). We injected $1.0 \mu \mathrm{l}$ of $15 \mu \mathrm{m}$ polystyrene microbeads (Invitrogen) into the anterior chamber of one eye to elevate IOP, while the contralateral eye received an equivalent volume of saline solution to serve as an internal control. A single injection was performed in all eyes.

For an in vivo drug study, we obtained adult (6- to 7-month-old) male Brown Norway rats from Charles River Laboratories and elevated IOP unilaterally again via microbead occlusion $(5 \mu \mathrm{l})$, with the opposing eye receiving an equivalent injection of saline solution, as described previously (Sappington et al., 2010; Dapper et al., 2013). We monitored IOP using TonoPen XL (Medtronic Solan), as previously described for rats (Sappington et al., 2010; Dapper et al., 2013). Two days before microbead injection, experimental and control animals $(n=8$ each) received, respectively, an intraperitoneal injection of either $1 \mathrm{mg} / \mathrm{kg}$ TRPV1-specific antagonist $\quad \mathrm{N}$-\{4-[6-(4-trifluoromethyl-phenyl)-pyrimidin-4-yloxy]benzothiazol-2-yl\}-acetamide (AMG-517, Amgen; Gavva et al., 2007; Tamayo et al., 2008; Wanner et al., 2012; drug was obtained courtesy of Alcon Research and Novartis) or its vehicle (3.6 g/L dibasic sodium phosphate dodecahydrate, $8 \mathrm{~g} / \mathrm{L}$ sodium chloride, $3.75 \mathrm{~g} / \mathrm{L}$ polysorbate 80 ). Animals were blindly assigned to either the treatment or vehicle cohort and were not reidentified until the experiments were completed. Treat- ment was repeated daily over an experimental period of 30-33 d to avoid hyperthermia induced by sporadic treatment (Gavva et al., 2007).

Tracing of anterograde axonal transport and tissue preparation. Fortyeight hours before perfusion, animals were anesthetized with $2.5 \%$ isoflurane and bilaterally injected intravitreally with $1 \mu \mathrm{l}$ (mice) or $2 \mu \mathrm{l}$ (rats) of $0.5 \mathrm{mg}$ cholera toxin subunit B (CTB) conjugated to Alexa Fluor 488 or 594 (Invitrogen) as previously described (Crish et al., 2010; Dapper et al., 2013). Two days postinjection, animals were transcardially perfused with PBS followed by $4 \%$ paraformaldehyde in PBS. For mice, retinas were dissected from the eyes, while a $3 \mathrm{~mm}$ section of optic nerve proximal to the globe was isolated, post-fixed for $1 \mathrm{~h}$ in $4 \%$ paraformaldehyde, and prepared for embedding and semi-thin cross-sectioning as described previously (Inman et al., 2006; Dapper et al., 2013). Brains of mice and rats were cryoprotected in $30 \%$ sucrose/PBS overnight, and 50 $\mu \mathrm{m}$ coronal midbrain sections were cut on a freezing sliding microtome. Serial sections of superior colliculus (SC) were imaged using a Ti Eclipse microscope (Nikon Instruments), and the intensity of the fluorescent CTB signal was quantified using ImagePro custom programming (Media Cybernetics) as previously described (Crish et al., 2010; Dapper et al., 2013). CTB signal was normalized to background, and intensity from alternating sections was calculated to reconstruct a retinotopic map of intact anterograde transport across the colliculus. The percentage of intact transport for each map was defined as the region of the colliculus with an intensity $\geq 70 \%$ of the maximum CTB signal for that tissue.

Retinal ganglion cell axon and body quantification. Photomicrographs of optic nerve cross sections were collected as montages on a Ti Eclipse microscope (Nikon Instruments) using $100 \times$ oil-immersion and differential interference contrast (DIC) optics. Using custom routines written for Image Pro (Media Cybernetics), images were contrast and edge enhanced. All axons with identifiable myelin sheaths were identified and counted. For assessing RGC body survival, whole-mounted retinas from a subset of the C57 and $\operatorname{Trpv} 1^{-1-}$ cohorts ( $n=5$ each) were immunolabeled using an antibody against phosphorylated neurofilament-heavy chain (SMI31, Sternberger Monoclonal). Images $\left(0.101 \mathrm{~mm}^{2}\right)$ of retinas were captured on an Olympus FV-1000 inverted confocal microscope along the midline of each retinal quadrant at $0.75,1.5,2.25$, and $3.0 \mathrm{~mm}$ from the optic disc following previously published methods (Lambert et al., 2011). SMI31-positive RGCs were counted in each image, and RGC density was calculated as cells per square millimeter.

Whole-cell patch-clamp recordings. Additional cohorts of both C57 $(n=15)$ and $\operatorname{Trpv1} 1^{-1-}(n=7)$ mice aged 8-10 weeks were obtained, and eyes were collected $25-28 \mathrm{~d}$ following our microbead occlusion paradigm, as described above. Retinas were removed, hemisected, and stored in oxygenated Ames' solution (Sigma-Aldrich) at room tempera- 

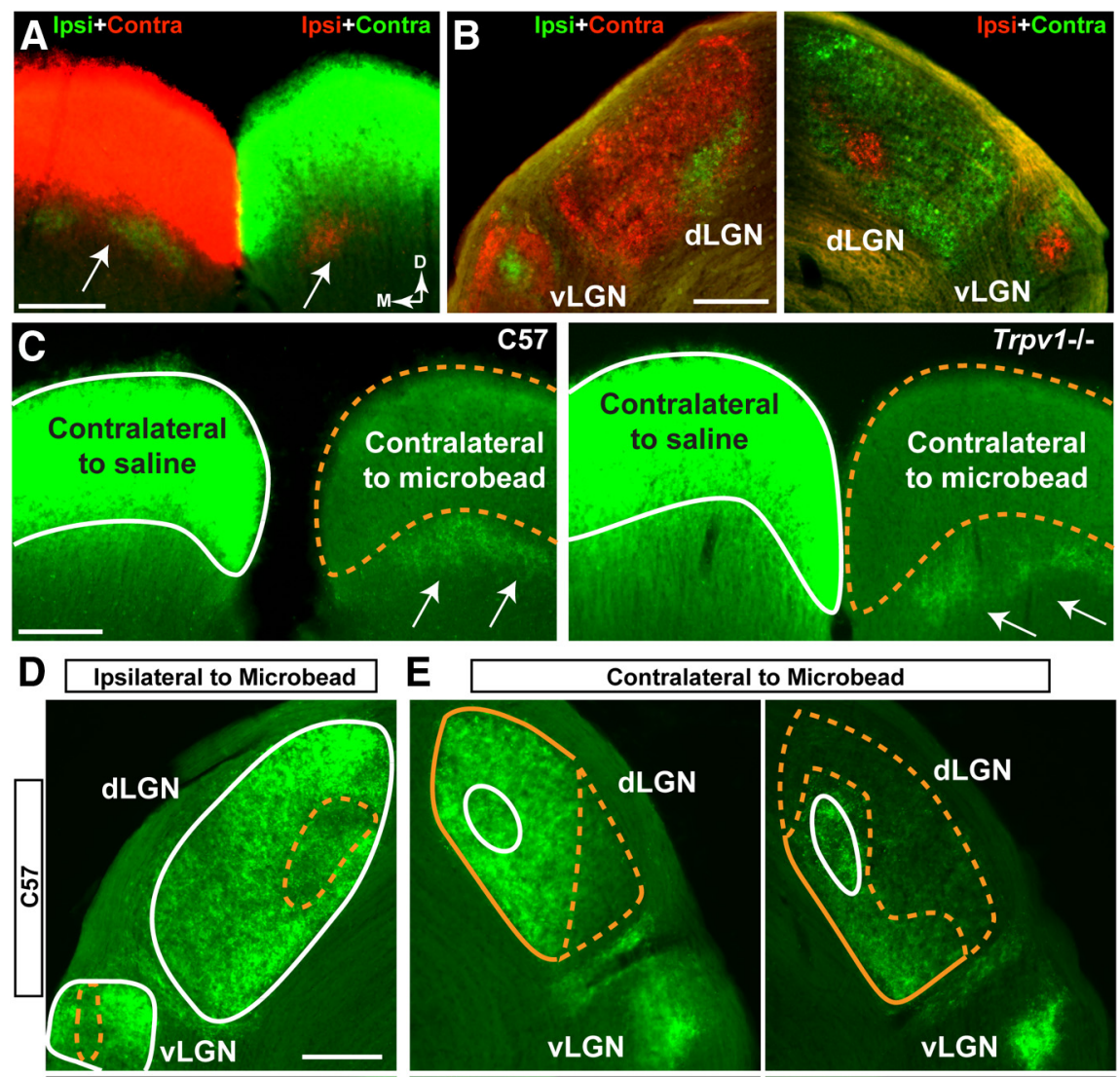

to Microbead

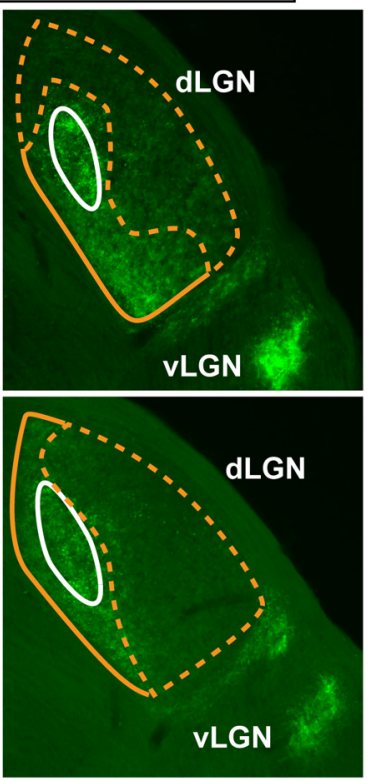

Figure 2. Microbead-induced IOP elevation causes deficits in anterograde transport to central brain structures. $A$, Coronal section shows both superior colliculi (SC) near rostral pole following bilateral intravitreal injection of CTB into left (green (TB) and right (red (TB) eyes of $(57$ mouse. Fluorescent signal for dominant contralateral projection is overexposed purposely to reveal sparser ipsilateral projection (arrows) for each eye. Medial (M) and dorsal (D) orientations indicated. B, Dorsal LGN (dLGN) and ventral LGN (vLGN) nuclei from same C57 brain show dominant contralateral with smaller ipsilateral projections. C, Coronal sections through the rostral pole of $\mathrm{C} 57$ (left) and Trpv $1^{-1-}$ (right) SCs show intact CTB signal (green) in the SC contralateral to saline injection (white outline). CTB signal in the SC contralateral to microbead injection (dashed yellow outline) is reduced after 5 weeks of elevated IOP. In SC, contralateral to microbead injection, the CTB signal in ipsilateral projections (arrows) remain intact, as expected. $\boldsymbol{D}, \boldsymbol{E}$, Coronal sections through LGN from $C 57$ mice (top row) and Trpv ${ }^{-1}$ - mice (bottom row) following bilateral intravitreal injections of CTB (green). $\boldsymbol{D}$, In the LGN ipsilateral to microbead-injected eye, CTB signal from saline-injected eyes remains intact (solid white outline), while the signal from microbead-injected eyes shows deficits embedded in both dLGN and vLGN (dashed yellow outline). Deficits appear worse in the Trpv1 - / - LGN. E, In LGNs contralateral to microbead-injected eye, CTB signal from saline-injected eyes is again intact (solid white outline). In the dLGN, CTB signal from microbead-injected eyes (yellow outlines) shows a range of deficits (dashed yellow). Once again, deficits appear worse in Trpv1 ${ }^{-1-} \mathrm{dLGN}$. The Trpv1 ${ }^{-1-} \mathrm{vLGN}$ also appears to have a lower CTB signal. Scale bars, $200 \mu \mathrm{m}$.

ture in the dark for a minimum of $30 \mathrm{~min}$. Retinal halves were transferred to a temperature-controlled perfusion chamber on an Olympus BX50 upright microscope equipped for fluorescent imaging with a $40 \times$ waterimmersion DIC objective (LUMPlanFI/IR, Olympus). Retinas were submerged with the ganglion cell layer up and perfused with Ames' solution at a rate of $2 \mathrm{ml} / \mathrm{min}$ in the dark at $24-25^{\circ} \mathrm{C}$. Cells in the retinal ganglion layer were whole-cell patch-clamped with borosilicate glass electrodes (5-10 M $\Omega$ ) containing the following (in $\mathrm{mm}$ ): K-gluconate $130, \mathrm{KCl} \mathrm{10}$, HEPES 10, $\mathrm{MgCl}_{2}$ 2, EGTA 1, $\mathrm{Na}_{2}$ ATP 2, and NaGTP 0.3. We included
1\% Lucifer yellow dye (Life Technologies) in the internal solution to verify that patched cells had an intact axon coursing toward the optic nerve head and to visualize dendritic morphology. A small subset of cells identified as amacrine cells were not included in the analysis.

We recorded spontaneous action potentials under current-clamp using an AxoClamp 2B microelectrode amplifier outfitted with pCLAMP software (Molecular Devices) for a minimum of $4 \mathrm{~min}$. For cells that did not show a spontaneous firing rate $>0.5 \mathrm{~Hz}$, a $1 \mathrm{~s}$ depolarizing step current ranging from 25 to $200 \mathrm{pA}$ was delivered at $0.1 \mathrm{~Hz}$ until the firing rate exceeded $3 \mathrm{~Hz}$, again for a minimum of $4 \mathrm{~min}$. Ganglion cells that did not achieve a consistent firing rate for a minimum of $4 \mathrm{~min}$ were excluded. We used a hyperpolarizing step of 25200 pA current to calculate membrane resistance. Recordings in which the membrane resistance changed by $>20 \%$ were not included in the final analysis.

Statistical analyses. Statistical comparisons between two independent measurements were made using two-sided $t$ tests, following confirmation of normality for each using the Shapiro-Wilk normality test; all datasets compared passed with $p \geq 0.22$ (SigmaPlot version 11.1, SYSTAT). Comparisons between multiple groups were made using Kruskal-Wallis one-way ANOVA on ranks (SigmaPlot version 11.1, SYSTAT). Numbers of samples and measurements along with actual $p$ values of significance are indicated where appropriate in the text or figure legends. All comparisons for which significance is reported achieved or exceeded a post hoc calculation of power of 0.80 .

\section{Results \\ Trpv1 $1^{-1-}$ accelerates axonopathy in the optic projection \\ We elevated IOP in C57 and Trpv1} mice by microbead occlusion of aqueous fluid in the anterior eye (Sappington et al., 2010; Chen et al., 2011). A single unilateral microbead injection elevated IOP by $\sim 33 \%$ for just $>5$ weeks ( $36 \mathrm{~d}$ ), while IOP from saline-injected fellow eyes remained near $15 \mathrm{mmHg}$ for the duration of the experiment (Fig. 1A). Trpv1 ${ }^{-1-}$ had no significant effect on IOP for either control or experimental eyes ( $p \geq 0.842$; Fig. $1 B)$.

$\operatorname{Tr} p v 1^{-1-}$ did, however, influence the response of the RGC projection to stress induced by elevated IOP. In naive C57 mice, RGC axonal transport of CTB injected intravitreally in both eyes reveals the dominant contralateral and lesser ipsilateral projections to the SC (Fig. $2 A$ ) and more proximal lateral geniculate nucleus (LGN; Fig. $2 B$ ). Following the period of IOP elevation, the SC projection from microbead-injected eyes in C57 and $\operatorname{Trp} v 1^{-1-}$ mice demonstrated deficits in CTB transport, while the projection from the saline-injected eye remained intact (Fig. 2C). Similarly, while CTB transport to the LGN from the saline-injected eye was intact (Fig. 2D), transport to the LGN 
from the microbead-injected eye decreased (Fig. 2E). Deficits in transport to the LGN in Trpv1 ${ }^{-1-}$ mice appeared more dramatic than in C57 mice.

Next, we compared the spatial progression of transport deficits in the SC, since in the microbead model this distal-most target in the RGC projection demonstrates transport deficits earliest (Crish et al., 2010). Following the period of IOP elevation, the SC of C57 mice demonstrated a partially intact retinotopic representation of axonal transport of CTB injected intravitreally (Fig. 3A). Depletion of transport progressed in sectors extending from the peripheral edge of the map toward the representation of the optic disc, consistent with our previous studies using this model (Crish et al., 2010). While anterograde transport from the control eyes was intact for both cohorts, the SC from microbeadinjected eyes of Trpv1 $1^{-1-}$ mice often demonstrated a nearly complete retinotopic loss (Fig. 3B). When quantified, each cohort exhibited a range in the magnitude of transport deficits with elevated IOP, as measured by the fraction of intact retinotopic map (Fig. 3C). However, the range for $\operatorname{Trpv1}^{-1-}$ mice was entirely $<50 \%$, while most C57 SC were above this point (Fig. $3 C$ ). Accordingly, deficits in Trpv1 $1^{-1-}$ SC were twice as severe as those in C57 mice, with average intact transport of $\sim 25 \%$ of the retinotopic map compared with just $>50 \%$ for C57 mice (Fig. 3D).

In models of glaucoma, outright degeneration of RGC axons in the optic nerve is subsequent to dysfunction in anterograde axonal transport to central structures like the SC and LGN (Calkins, 2012). We found that with elevated IOP, cross sections of C57 optic nerve demonstrated early signs of pathological progression such as degenerating axon profiles and diminished packing (Fig. 4A). Nerves from Trpv1 ${ }^{-1-}$ mice exhibited accelerated pathology, with the most extreme samples from the cohort accented by a pronounced increase in degenerating profiles, thinning of axon packing, and overt hypertrophy of astrocyte processes (Fig. 4B). Nerves from the saline-injected eyes of the two cohorts appeared similar.

Axon density in nerves from control C57 eyes ranged from 384,000 to 538,000 axons $/ \mathrm{mm}^{2}$ (Fig. 4 C), consistent with previous studies (Sappington et al., 2010). Microbead elevation shifted this range to from 277,000 to 477,000 axons $/ \mathrm{mm}^{2}$. Trpv1 ${ }^{-1-}$ had no effect on axon density in the saline-injected nerve, but, like transport to the SC, exacerbated the reduction caused by elevated IOP. Some nerves from microbead-injected eyes retained a density of $\leq 110,000$ axons $/ \mathrm{mm}^{2}$ (Fig. 4 C). On average, elevated IOP reduced axon density in C57 optic nerves by $14 \%$ compared with saline-injected nerves $(p=0.029$; Fig. $4 D)$. Trpv1 $1^{-1-}$ microbead-injected nerves exhibited a $47 \%$ decrease in density compared with their saline counterparts $(p<0.001$; Fig. $4 D)$. This decrease in axon density was accompanied by a small decrease $(\sim 14 \%)$ in cross-sectional nerve area only in $\operatorname{Trpv1} 1^{-1-}$ mice (Fig. 4E). Finally, we estimated the total number of axons in each nerve by multiplying axon density by nerve cross-sectional area. This yielded a range of 32,000-54,000 axons in nerves from saline-injected eyes from both cohorts (data not shown), which again is consistent with previous studies (Sappington et al., 2010). The corresponding mean was 41,659 axons for C57 mice ( \pm 2700 axons) and 42,990 axons for Trpv1 ${ }^{-1-}$ mice ( \pm 1917 axons; Fig. $4 F)$. On average, elevated IOP reduced the number of axons in C57 optic nerves by $17 \%$ compared with saline-injected nerves $(p=0.04$; Fig. $4 F)$. The Trpv1 ${ }^{-1-}$ microbead nerves exhibited a far worse effect, with an average $53 \%$ loss of axons $(p<0.001$; Fig. $4 F)$.
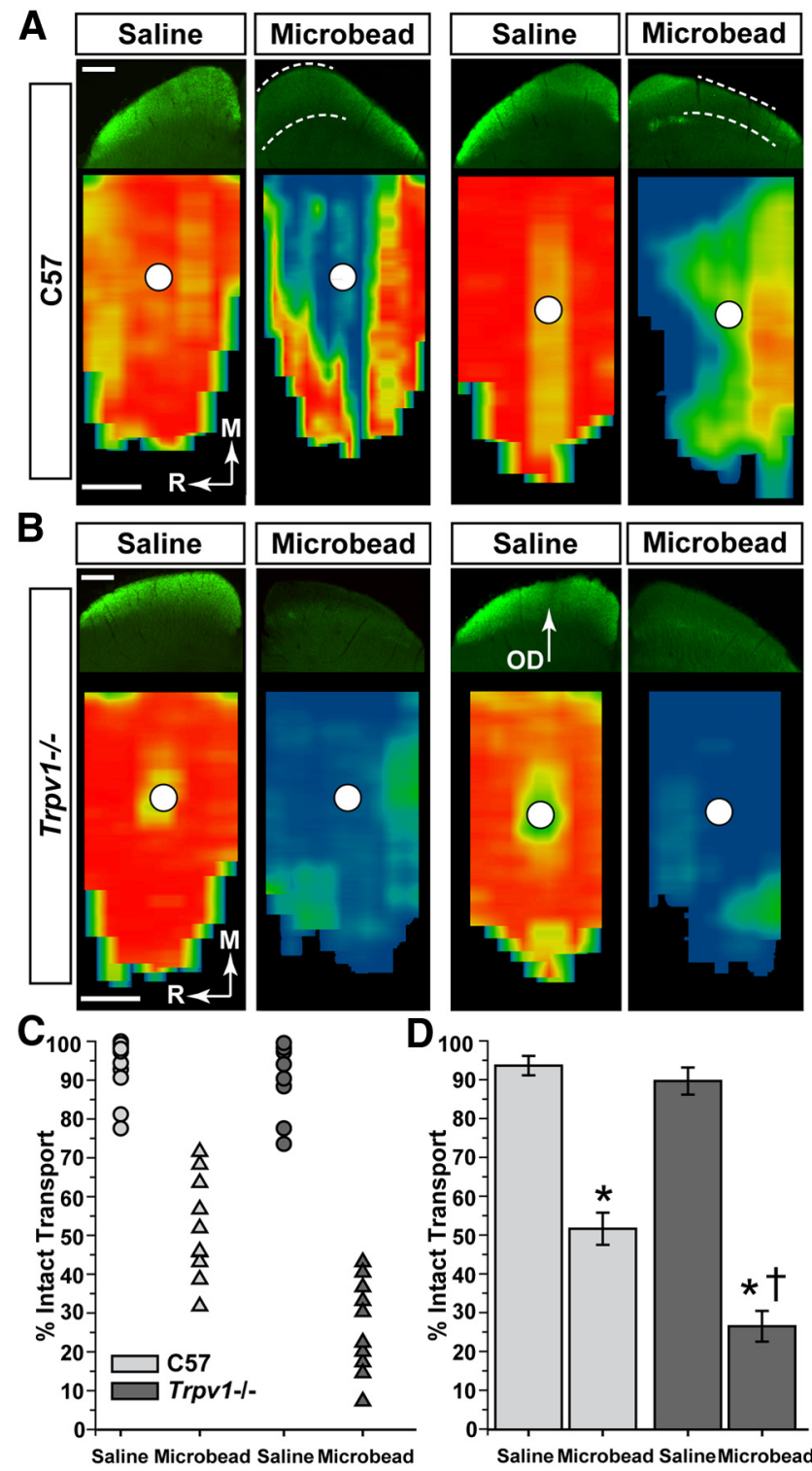

Figure 3. Trpv1 ${ }^{-1}$ - exacerbates deficits in anterograde axonal transport. $\boldsymbol{A}$, Top row, Coronal sections through SC following intravitreal injection of CTB (green) into saline- and microbead-injected eyes of $\mathrm{C} 57$ mice. Microbead-induced IOP elevation (Fig. 1) induced deficits in anterogradely transported CTB (dotted lines). Bottom row, Retinotopic maps reconstructed from serial sections of SC with optic disc gap indicated (circles). Density of the signal from transported CTB ranges from $0 \%$ (blue) to $50 \%$ (green) to $100 \%$ (red). Medial (M) and rostral (R) orientations are indicated. $\boldsymbol{B}$, Top row, Sagittal SC sections from Trpv $1^{-1-}$ mice with microbead-induced IOP elevations show worse deficits in CTB transport compared with C57. Corresponding retinotopic maps (bottom row) demonstrate nearly complete loss of CTB transport. OD, Optic disc representation (no RGCs). Scale bars: $\boldsymbol{A}, \boldsymbol{B}, 500 \mu \mathrm{m}$. $\boldsymbol{C}$, Fraction of the retinotopic map with intact $R G C$ axonal transport (defined by $\geq 70 \%$ CTB signal) to individual C57 and Trpv $1^{-1-}$ saline-injected ( $n=10$ and 8, respectively) and microbead-injected ( $n=$ 10 and 10, respectively) superior colliculi. $\boldsymbol{D}$, Transport of (TB from saline-injected eyes was near $100 \%$ and similar for C57 (93.8 $\pm 2.5 \%)$ and Trpv ${ }^{-1-}(90 \pm 3.5 \%)$ cohorts (mean \pm SEM; $p=0.46$, two-sided $t$ test). Intact transport in SC following IOP elevation was reduced in both cohorts compared with the saline-injected eyes ( ${ }^{*} p<0.001$, two-sided $t$ test), but the decrease in Trpv1 ${ }^{-1-}(26.6 \pm 4.0 \%)$ was twice as severe as in 57 mice $(51.7 \pm 4.1 \% ; \uparrow p<0.001$, two-sided $t$ test). Legend is as in $\boldsymbol{C}$.

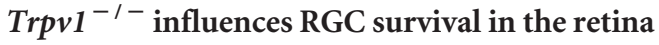

RGC somal degeneration in the retina follows optic nerve axonopathy in both chronic and inducible models of glaucoma, including the microbead model used here (Calkins, 2012). The 5 week duration of IOP elevation in our cohorts did not induce 

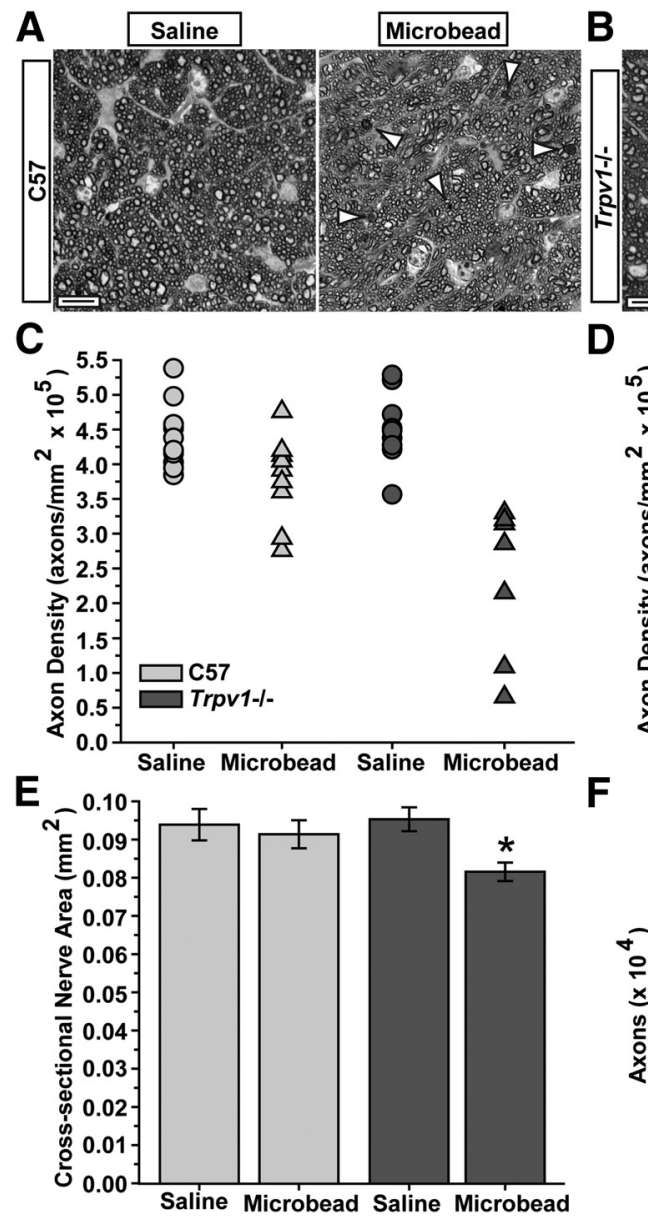

F
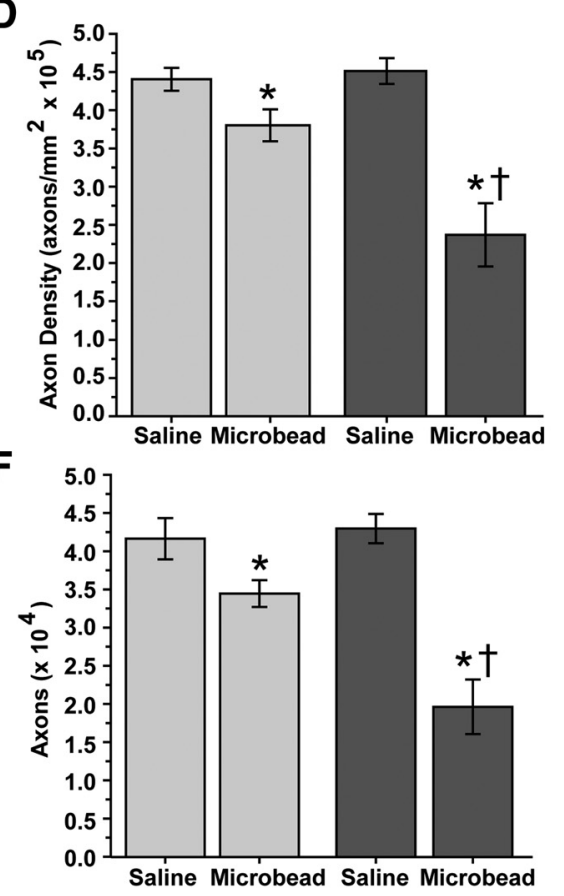

Figure 4. Trpv1 ${ }^{-1-}$ mice exhibit more severe optic nerve pathology following elevated IOP. A, Cross sections of C57 optic nerve from saline- and microbead-injected eyes. Microbead-induced elevated IOP yielded a modest reduction in the packing density of intact axons and increased the incidence of degenerating axonal profiles (arrowheads). B, Cross section through Trpv $1^{-1-}$ optic nerve from microbead-injected eye shows severely diminished axon packing, overt gliosis (arrows), and far more degenerating profiles compared with (57 nerves (arrowheads). Saline-injected eye nerves from the two cohorts appear similar. Scale bars: $\boldsymbol{A}, \boldsymbol{B}, 10 \mu \mathrm{m}$. C, Density of intact axons in cross sections through individual C57 and Trpv ${ }^{-1}$ - saline-injected ( $n=10$ and 9 , respectively) and microbead-injected ( $n=9$ and 7, respectively) optic nerves quantified from cross sections, as shown in $A$ and $\boldsymbol{B}$. D. Mean ( \pm SEM) axon density in $\left(57\right.$ and Trpv $1^{-1-}$ optic nerves. Diminished density from microbead-induced IOP elevation in Trpv $1^{-1-}$ nerves is more than twice that of $C 57$ nerves ( $t p<0.001$, two-sided $t$ test). *Significance for microbead compared with corresponding saline nerve $\left(^{*} p=0.001\right.$ for $\left(57 ; p<0.001\right.$ for Trpv ${ }^{-1}$, , two-sided $t$ test). E, Cross-sectional area (mean \pm SEM) of Trpv1 ${ }^{-1-}$ optic nerves shrinks with elevated IOP compared with saline-injected eyes. ${ }^{*} p=0.005$, two-sided $t$ test. $\boldsymbol{F}$, Number of axons (mean \pm SEM) calculated as a product of nerve area and axon density. Trpv ${ }^{-1-}$ nerves have nearly twice the loss compared with $C 57$ nerves with elevated IOP ( $t p<0.001$, two-sided $t$ test), though both groups have fewer axons compared with saline-injected nerves ( ${ }^{*} p=0.03$ for $\left(57\right.$ and $p=0.04$ for $\operatorname{Trpv}{ }^{-1}$, , two-sided $t$ test). Number of axons in saline-injected nerves was similar in two cohorts ( $p=0.70$, two-sided $t$ test). Legend applies to $\boldsymbol{C}-\boldsymbol{F}$.

large-scale RGC body loss in either retina (Fig. $5 A, B$ ), though accumulation of phosphorylated neurofilaments tended to be worse for the Trpv1 $1^{-1-}$ mice (Fig. 5C). We have previously demonstrated that initial deficits in anterograde transport are not due to reduced uptake of CTB by RGCs, in both chronic and inducible models (Crish et al., 2010; Lambert et al., 2011; Dapper et al., 2013). Similarly, RGC uptake of CTB is not affected by Trpv1 $1^{-1-}$ in either saline-injected or microbead-injected retinas-nearly every RGC contains a label (Fig. 5B). Even for the Trpv1 ${ }^{-1-}$ SC with the worst intact transport of CTB with IOP elevation (Fig. $3 C, 9 \%$ ), the number of RGCs labeled by CTB uptake was the same as that labeled against phosphorylated neurofilaments $(p=$ 0.51 ; data not shown). We therefore cannot attribute the transport deficits we see in the colliculus to an apparent difference in CTB uptake between cohorts.
Moreover, when quantified across retinal quadrants, for most distances from the optic nerve head, neither cohort showed significant RGC body loss (Fig. $5 D)$. At most locations, the ratio of RGC body density in the two eyes did not differ from unity, though there was a certain degree of variability. However, in microbeadinjected retinas from $\operatorname{Tr} p v 1^{-1-}$ mice, accelerated loss was observed in the nasal quadrant; the most pronounced loss was nearest the optic disc with $40 \pm 7 \%$ reduction compared with the saline-injected eye $(p=0.03)$. At the same location, reduction in the C57 microbead-injected retina was $24 \pm 11 \%$, which was not significant $(p=0.20)$. Thus, in both the optic projection and the retina, $\operatorname{Tr} p v 1^{-/-}$ accelerates RGC degeneration associated with elevated IOP.

The results in Figure 5 also complement our previous work in which rats with elevated IOP for a similar duration exhibited reduced RGC density in the nasal quadrant (Lambert et al., 2011). Importantly, the deficits in axonal transport to the SC we quantified in Figure 3 also tended to progress from the nasal quadrant (Fig. 6). This indicates that the retinotopic pattern of degeneration is conserved, as progression advances from distal sites in the optic projection to the retina.

\section{Antagonism of TRPV1 also accelerates RGC axonopathy}

An earlier study (Nucci et al., 2007) indicated that pharmacological antagonism of TRPV1 worsened RGC survival with transient ischemia induced by acutely elevated IOP. Here, we elevated IOP in rats for just $<5$ weeks (30-33 d) once again using microbead occlusion as described previously (Dapper et al., 2013). Microbead-injected eyes demonstrated a 33\% elevation compared with saline-injected eyes for rats treated systemically with a highly selective and potent TRPV1 antagonist (Gavva et al., 2007; Tamayo et al., 2008; Wanner et al., 2012; AMG-517); in the vehicle cohort, elevation was 35\% (Fig. 7A; $p=0.10$ ). Despite this similarity, drug-treated rats demonstrated deficits in CTB transport to the SC with elevated IOP that were obviously more dramatic than deficits in vehicle-injected SC, even in single coronal sections (Fig. $7 B$ ). The corresponding retinotopic maps of intact CTB transport for the drug cohort showed large swaths of SC with little or no signal with microbead elevation; the salineinjected eye SCs were unaffected in both cohorts (Fig. 7C). Transport deficits, though not as severe in magnitude as those in mice despite comparable IOP elevation and only slightly shorter duration (Fig. 7C), progressed through entire sectors; this is consistent with our previous studies in microbead rats (Dapper et al., 2013). Even so, when quantified, transport deficits in the drug cohort were 2.5 times as severe as deficits in vehicle-treated rats (Fig. $7 D$; 
$p=0.04)$. Thus, similar to our findings with $\operatorname{Trpv1} 1^{-1-}$ mice (Fig. 3), systemic pharmacological antagonism of TRPV1 accelerates the loss of anterograde transport from the retina to the SC.

\section{Trpv1 ${ }^{-1-}$ reduces RGC action} potential rate in response to stress

Next, we probed the mechanism through which Trpv1 ${ }^{-1-}$ might accelerate RGC degeneration. We once again elevated IOP in C57 and Trpv1 ${ }^{-1-}$ mice, and used patch-clamp recording to compare the physiological activity of single RGCs (Fig. 8). Again, microbead injection elevated IOP by $33 \%$ compared with saline injection (compare Fig. 1, 8), and IOP was monitored for a period of 25-28 d (Fig. $8 A)$. RGC morphology was visualized with Lucifer yellow, and consistently demonstrated an intact axon and complex dendritic arborization, regardless of strain (Fig. 8B). While a detailed analysis of morphology is pending, we did not note any obvious structural differences between C57 and Trpv1 ${ }^{-1-}$ RGCs. For C57 and $\operatorname{Trpv1} 1^{-1-}$ retinas, respectively, this included a mixture of RGCs with arbors stratifying in the OFF (43 and 38\%), ON (15 and $21 \%$ ), or both (41 and $41 \%$ ) layers of the inner plexiform layer.

$\operatorname{Trpv1} 1^{-1-}$ fundamentally changed the physiological response of RGCs exposed to elevated IOP. In our sample of 130 RGCs, approximately half (49\%) had relatively high spontaneous rates of action potential generation $(3-15 \mathrm{~Hz})$ in the absence of any further stimulation. This subset contained a mixture of RGCs with ON, OFF, or ON/OFF stratification. RGCs from C57 retina demonstrated an approximately twofold increase in spontaneous rate on average following the period of microbeadinduced IOP elevation compared with RGCs from saline-injected eyes (Fig. 8C). This did not occur in Trpv1 ${ }^{-1-}$ microbeadinjected retinas, which instead demonstrated an apparent decrease in activity compared with the saline-injected eye (Fig. $8 C$ ). When quantified across experiments (Fig. 8D), the rate for C57 microbead RGCs was actually $120 \%$ higher than for RGCs in saline-injected retinas $(p=0.025)$. While the spontaneous rate for RGCs in C57 and Trpv1 ${ }^{-1-}$ saline-injected retinas did not differ $(p=0.64)$, the rate for $\operatorname{Tr} p v 1^{-1-}$ microbead RGCs was $65 \%$ less than RGCs in C57 microbead-injected retinas ( $p=$ 0.006). Compared with saline-injected RGCs, the rate in

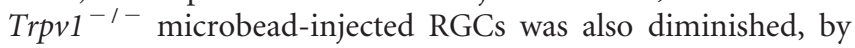
$42 \%$. However, this difference was not significant $(p=0.33$ ).

The remaining $51 \%$ of our RGC sample demonstrated very low spontaneous rates of firing $(<0.5 \mathrm{~Hz})$. This subset contained about the same fraction of RGCs with ON, OFF, or ON/OFF stratification as the set of RGCs with a higher spontaneous rate (Fig. $8 C, D$ ). For these, we injected depolarizing current in increments of $25 \mathrm{pA}$ until the rate exceeded $3 \mathrm{~Hz}$. Typically, RGCs in this category required a step of 25 or $50 \mathrm{pA}$ in amplitude-except for RGCs from Trpv1 $1^{-1-}$ microbead-injected retinas, which more often required 50, 75, or $100 \mathrm{pA}$ (Fig. $8 E$ ). When averaged across experiments (Fig. 8F), RGCs from C57 saline- and microbead-injected retinas were similar to RGCs from $\operatorname{Trpv1} 1^{-1-}$ saline-injected retinas, with means ranging from 35 to $43 \mathrm{pA}$ ( $p=$ $0.86)$. However, $\operatorname{Trpv1} 1^{-1-}$ microbead-injected RGCs required $\sim 62 \%$ more current to reach the threshold firing rate ( $p \leq$ 0.011). Thus, with elevated IOP, RGCs from Trpv1 ${ }^{-1-}$ retinas demonstrate not only less spontaneous activity, but also require more excitation to generate action potentials.

\section{Discussion}

Our fundamental result is quite striking: for an equivalent stressor, in this case elevated pressure in the eye, the absence of functional TRPV1 accelerates neurodegeneration. An early characteristic of neurodegeneration in glaucoma is degradation of active transport from the retina to the colliculus, which occurs before outright axon degeneration in the optic nerve (Crish et al., 2010; Lambert et al., 2011; Dapper et al., 2013). After a 5 week period of an equivalent elevation in IOP (33\%; Fig. 1), both deficits in anterograde transport to the colliculus (Fig. 3) and degeneration of axons in the optic nerve (Fig. 4) were about twice as severe in $\operatorname{Trpv1} 1^{-1-}$ mice than in age-matched C57 mice. Similar to other neurodegenerative diseases, axonopathy is among the earliest pathogenic events in glaucoma, with RGC body loss in the retina following later (Whitmore et al., 2005; Calkins, 2012; Howell et al., 2012). This period is especially pronounced in models using modest elevations in IOP, including the microbead model used here (Calkins, 2012; Dapper et al., 2013). Thus, while 

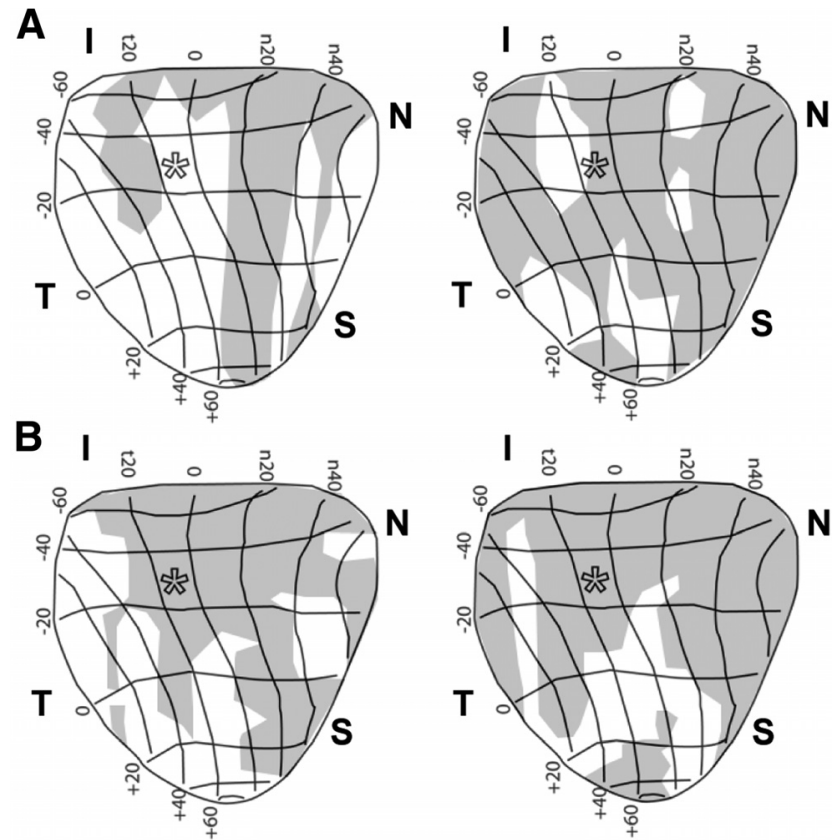

Figure 6. Microbead-induced anterograde transport deficits in SCS are retinotopically sectorial. $\boldsymbol{A}, \boldsymbol{B}$, Retinotopic maps of $C 57(\boldsymbol{A})$ and $\operatorname{Trpv}^{-1-}(\boldsymbol{B})$ SCs from microbead-injected eyes show progression of transport deficits (shaded regions) by retinal quadrant and eccentricity. Deficits in 57 mice (43\% and 68\%, left and right, respectively) progress from the nasal (N) fields toward other sectors and the representation of optic disk (*). Deficits in Trpv1 ${ }^{-1}$ SCs are more severe ( $69 \%$ and $81 \%$, left and right, respectively), covering nearly all of the nasal quadrant from inferior (I) to superior (S) fields. The temporal (T) field is most often the last affected in both mouse strains. SC maps transformed into retinal quadrant and eccentricity coordinates are as specified by Siminoff et al. (1966) and Dräger and Hubel (1976).

in C57 retinas RGC body dropout was hardly detectable, $\operatorname{Trp} v 1^{-1-}$ retinas demonstrated a modest yet significant loss in the nasal quadrant, especially in the region of normally highest RGC density near the optic nerve head (Fig. 5). This extra susceptibility of the nasal quadrant (Fig. 6), while not yet understood, is consistent with results from other rodent models (Lambert et al., 2011). In rats with microbead-induced elevated pressure, we found that, like $\operatorname{Tr} p v 1^{-1-}$, pharmacological antagonism of TRPV 1 also accelerated deficits in axonal transport to the colliculus (Fig. 7). Interestingly, in none of our results is there an indication that either Trpv1 $1^{-1-}$ or TRPV1 antagonism affects RGC survival in the absence of stress associated with elevated IOP. This suggests that TRPV1 activation contributes primarily to survival via stress-activated pathways, a possibility we have reviewed recently (Ho et al., 2012).

In terms of possible mechanisms, TRPV1 in isolated RGCs exposed to elevated hydrostatic pressure in vitro mediates an increase in intracellular $\mathrm{Ca}^{2+}$ that induces apoptotic death; both antagonism of TRPV1 and chelation of extracellular $\mathrm{Ca}^{2+}$ significantly reduce this response (Sappington et al., 2009). Here, we found that RGCs from C57 retinas exposed to elevated IOP for a period of 4 weeks demonstrated a significant increase in spontaneous firing of action potentials compared with their saline-injected retina counterparts (Fig. 8C,D); RGCs from $\operatorname{Trp} v 1^{-1-}$ retinas lacked this response entirely. Similarly, RGCs with low spontaneous firing rates from $\operatorname{Trp} v 1^{-1-}$ microbeadinjected retinas required a greater depolarizing current to drive a threshold rate than RGCs in $\mathrm{C} 57$ retinas (Fig. $8 E, F$ ). Thus, the absence of TRPV1 abolishes an intrinsic physiological mechanism that enhances RGC excitatory signaling under conditions that stress the neuron, especially the axon.
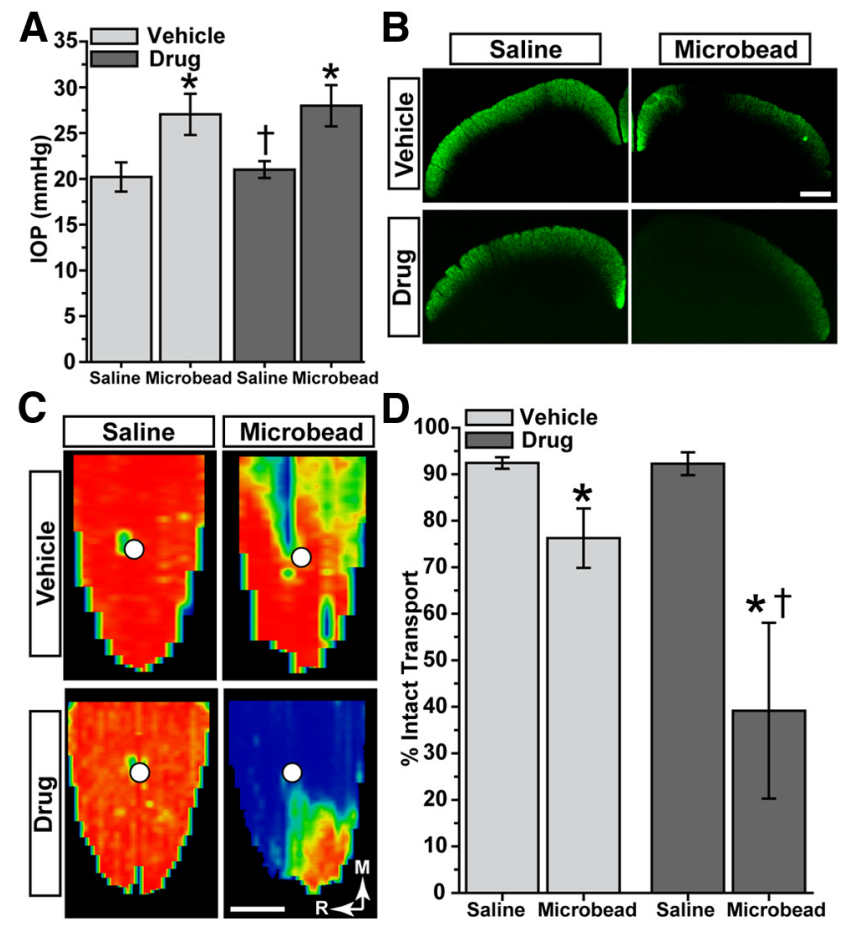

Figure 7. TRPV1 antagonism accelerates RGC axonal transport deficits in rats. $\boldsymbol{A}, 10 \mathrm{P}$ in two cohorts of rats was elevated for $<5$ weeks $(30-33 \mathrm{~d}$ ) following microbead injection (5.0 $\mu \mathrm{l})$; the opposing eye received an equivalent volume of saline. Elevation (mean $\pm S E M$ ) compared with saline-injected eyes in both vehicle $(27.04 \pm 0.14$ vs $20.20 \pm 0.14 \mathrm{mmHg})$ and drug $(27.99 \pm 0.26$ vs $21.01 \pm 0.10 \mathrm{mmHg})$ cohorts was significant $\left({ }^{*} p<0.001\right.$, two-sided $t$ test for each cohort). Between the two cohorts, IOP was similar for microbead-injected eyes ( $p=$ 0.10 ), but was slightly higher in the drug saline-injected eye ( $t p=0.001$, two-sided $t$ test for each). $B$, Coronal SC sections from rats treated with TRPV1 antagonist show worse deficits in CTB transport with microbead-induced IOP elevations compared with vehicle rats. C, Corresponding retinotopic maps demonstrate accelerated progression in transport deficits for the drug group. The color scheme is as in Figure 3. D, Fraction of the retinotopic SC map with intact transport (defined by $\geq 70 \%$ (TB signal) from saline-injected eyes was similar for vehicle ( $92.4 \pm 1.2 \%$ ) and drug $(92.3 \pm 2.4 \%)$ cohorts (mean \pm SEM; $p=0.93$, two-sided $t$ test). Intact transport in SC following IOP elevation was reduced in both cohorts compared with the saline-injected eye $\left(^{*} p \leq 0.04\right.$, two-sided $t$ test), but the decrease with drug treatment ( $39.2 \pm 18.9 \%$ intact) was more severe than with vehicle $(76.3 \pm 6.4 \%$ intact; $\uparrow p=0.04$, two-sided $t$ test). Scale bars: $\boldsymbol{B}$, c, $500 \mu \mathrm{m}$.

Interestingly, our results using patch-clamp recordings from single C57 RGCs contrast with recent results using extracellular multielectrode arrays, in which microbead-induced elevations in IOP for a similar duration to ours caused a decrease in RGC spontaneous firing (Della Santina et al., 2013). One possible reason is simple sampling. By necessity, patch-clamp recordings result in far fewer cells than multielectrode recordings. At this point, we cannot exclude the possibility that RGCs that did not meet our criteria for consistency in firing rate and membrane resistance might have been more pathological than those that did meet our criteria for inclusion. The multielectrode array recordings, also by necessity, use a much higher bath temperature than ours to maximize spike amplitude (Della Santina et al., 2013). This could influence how TRPV1 in C57 RGCs contributes to excitation, since the channel can be sensitive to temperature (Sharif-Naeini et al., 2008). We are pursuing a more detailed study now to resolve these issues and also to determine whether in a larger sample RGC morphological subtypes differ in their susceptibility to IOP-related stress.

We propose that TRPV1 plays an early, $\mathrm{Ca}^{2+}$-dependent role in detecting stress associated with elevated pressure in glaucoma, 
to mediate a compensatory response to counter disease progression. In isolated systems (e.g., purified RGCs) in which the pressure stressor is acute, TRPV1 activation is sufficient to induce an apoptotic increase in intracellular $\mathrm{Ca}^{2+}$ (Sappington et al., 2009). In the intact system, the same activation by a modest chronic stressor would seem to initiate protective cascades that at least in part boost RGC excitation as measured by rate of firing. Thus, progression is accelerated with Trpv1 $1^{-1-}$. This model is consistent with other in vivo results in which pharmacological antagonism of TRPV1 ablated the protection afforded by an anandamide analog on RGC survival with ischemicreperfusion injury induced by acutely elevated IOP (Nucci et al., 2007). Our hypothesis is also supported by recent work showing that the TRPC6 channel is protective in a model of retinal ischemia/ reperfusion injury (Wang et al., 2010).

We do not yet understand all possible mechanisms through which TRPV1 could counter neuronal stress, though both neuronal and glial mechanisms are likely (Ho et al., 2012). TRPV1 can be activated and/or sensitized either directly by mechanical stress or by endogenous ligands like endocannabinoids and growth factors (Straiker et al., 1999; Stamer et al., 2001; Zhang et al., 2005). In addition to RGCs, TRPV1 is expressed in both astrocytes and microglia of the retina (Leonelli et al., 2009; Sappington et al., 2009). Activation in retinal microglia is coupled to the release of interleukin-6, which is protective of isolated RGCs exposed to elevated pressure (Sappington et al., 2006; Sappington and Calkins, 2008). The endogenous cannabinoid anandamide is a ligand for both TRPV1 and the cannabinoid type 1 receptor, and is known to protect against ischemic injury and excitotoxicity (Kim et al., 2007). TRPV1 and the anandamide precursor enzyme $N$-arachidonoyl phosphatidylethanolamine-phospholipase D are expressed in the RGC projection to the colliculus (Maione et al., 2009), the primary target for RGCs in the rodent visual system. Thus, TRPV1 could help counter progression through axonal mechanisms outside of the retinal milieu.

With stress, neuronal TRPV1 is upregulated and undergoes translocation to the plasma membrane, where it increases postsynaptic neurite activity and survival (Zhang et al., 2005; Biggs et al., 2008; Goswami et al., 2010; Schumacher and Eilers, 2010). Once translocated, TRPV1-gated $\mathrm{Ca}^{2+}$ promotes spontaneous excitation and potentiates postsynaptic responses to glutamate (Marinelli et al., 2003; Xing and Li, 2007; Medvedeva et al., 2008; Jiang et al., 2009; Peters et al., 2010). This is similar to the enhancement we observed in our physiological recordings (Fig. 8). Phosphorylation promotes sensitization, continued translocation, and increased depolarization (Van Buren et al., 2005). TRPV1 can become desensitized by dephosphorylation via the calmodulin-dependent protein phosphatase calcineurin or by reinternalization (Mohapatra and Nau, 2005). Together, these results suggest that TRPV1 could contribute to RGC survival in response to stress or injury by using both extrinsic and intrinsic signaling mechanisms.

\section{References}

Aarts MM, Tymianski M (2005) TRPMs and neuronal cell death. Pflugers Arch 451:243-249. CrossRef Medline

Agopyan N, Head J, Yu S, Simon SA (2004) TRPV1 receptors mediate particulate matter-induced apoptosis. Am J Physiol Lung Cell Mol Physiol 286:L563-L572. CrossRef Medline

Biggs JE, Yates JM, Loescher AR, Clayton NM, Robinson PP, Boissonade FM (2008) Effect of SB-750364, a specific TRPV1 receptor antagonist, on injury-induced ectopic discharge in the lingual nerve. Neurosci Lett 443 : 41-45. CrossRef Medline

Calkins DJ (2012) Critical pathogenic events underlying progression of neurodegeneration in glaucoma. Prog Retin Eye Res 31:702-719. CrossRef Medline

Caterina MJ, Leffler A, Malmberg AB, Martin WJ, Trafton J, Petersen-Zeitz KR, Koltzenburg M, Basbaum AI, Julius D (2000) Impaired nociception and pain sensation in mice lacking the capsaicin receptor. Science 288: 306-313. CrossRef Medline

Chen H, Wei X, Cho KS, Chen G, Sappington R, Calkins DJ, Chen DF (2011) Optic neuropathy due to microbead-induced elevated intraocular pressure in the mouse. Invest Ophthalmol Vis Sci 52:36-44. CrossRef Medline

Ciura S, Bourque CW (2006) Transient receptor potential vanilloid 1 is required for intrinsic osmoreception in organum vasculosum lamina terminalis neurons and for normal thirst responses to systemic hyperosmolality. J Neurosci 26:9069-9075. CrossRef Medline

Crish SD, Sappington RM, Inman DM, Horner PJ, Calkins DJ (2010) Distal axonopathy with structural persistence in glaucomatous neurodegeneration. Proc Natl Acad Sci U S A 107:5196-5201. CrossRef Medline

Daly D, Rong W, Chess-Williams R, Chapple C, Grundy D (2007) Bladder 
afferent sensitivity in wild-type and TRPV1 knockout mice. J Physiol 583:663-674. CrossRef Medline

Dapper JD, Crish SD, Pang IH, Calkins DJ (2013) Proximal inhibition of p38 MAPK stress signaling prevents distal axonopathy. Neurobiol Dis 59C:26-37. CrossRef Medline

Della Santina L, Inman DM, Lupien CB, Horner PJ, Wong RO (2013) Differential progression of structural and functional alterations in distinct retinal ganglion cell types in a mouse model of glaucoma. J Neurosci 33:17444-17457. CrossRef Medline

Dräger UC, Hubel DH (1976) Topography of visual and somatosensory projections to mouse superior colliculus. J Neurophysiol 39:91-101. Medline

Gavva NR, Bannon AW, Hovland DN Jr, Lehto SG, Klionsky L, Surapaneni S, Immke DC, Henley C, Arik L, Bak A, Davis J, Ernst N, Hever G, Kuang R, Shi L, Tamir R, Wang J, Wang W, Zajic G, Zhu D, et al (2007) Repeated administration of vanilloid receptor TRPV1 antagonists attenuates hyperthermia elicited by TRPV1 blockade. J Pharmacol Exp Ther 323:128137. CrossRef Medline

Goswami C, Rademacher N, Smalla KH, Kalscheuer V, Ropers HH, Gundelfinger ED, Hucho T (2010) TRPV1 acts as a synaptic protein and regulates vesicle recycling. J Cell Sci 123:2045-2057. CrossRef Medline

Ho KW, Ward NJ, Calkins DJ (2012) TRPV1: a stress response protein in the central nervous system. Am J Neurodegener Dis 1:1-14. Medline

Howell GR, Soto I, Zhu X, Ryan M, Macalinao DG, Sousa GL, Caddle LB, MacNicoll KH, Barbay JM, Porciatti V, Anderson MG, Smith RS, Clark AF, Libby RT, John SW (2012) Radiation treatment inhibits monocyte entry into the optic nerve head and prevents neuronal damage in a mouse model of glaucoma. J Clin Invest 122:1246-1261. CrossRef Medline

Hwang SJ, Burette A, Rustioni A, Valtschanoff JG (2004) Vanilloid receptor VR1-positive primary afferents are glutamatergic and contact spinal neurons that co-express neurokinin receptor NK1 and glutamate receptors. J Neurocytol 33:321-329. CrossRef Medline

Inman DM, Sappington RM, Horner PJ, Calkins DJ (2006) Quantitative correlation of optic nerve pathology with ocular pressure and corneal thickness in the DBA/2 mouse model of glaucoma. Invest Ophthalmol Vis Sci 47:986-996. CrossRef Medline

Jiang CY, Fujita T, Yue HY, Piao LH, Liu T, Nakatsuka T, Kumamoto E (2009) Effect of resiniferatoxin on glutamatergic spontaneous excitatory synaptic transmission in substantia gelatinosa neurons of the adult rat spinal cord. Neuroscience 164:1833-1844. CrossRef Medline

Jones RC 3rd, Xu L, Gebhart GF (2005) The mechanosensitivity of mouse colon afferent fibers and their sensitization by inflammatory mediators require transient receptor potential vanilloid 1 and acid-sensing ion channel 3. J Neurosci 25:10981-10989. CrossRef Medline

Kim SR, Kim SU, Oh U, Jin BK (2006) Transient receptor potential vanilloid subtype 1 mediates microglial cell death in vivo and in vitro via $\mathrm{Ca} 2+$-mediated mitochondrial damage and cytochrome c release. J Immunol 177:4322-4329. Medline

Kim SR, Chung YC, Chung ES, Park KW, Won SY, Bok E, Park ES, Jin BK (2007) Roles of transient receptor potential vanilloid subtype 1 and cannabinoid type 1 receptors in the brain: neuroprotection versus neurotoxicity. Mol Neurobiol 35:245-254. CrossRef Medline

Lambert WS, Ruiz L, Crish SD, Wheeler LA, Calkins DJ (2011) Brimonidine prevents axonal and somatic degeneration of retinal ganglion cell neurons. Mol Neurodegener 6:4. CrossRef Medline

Leonelli M, Martins DO, Kihara AH, Britto LR (2009) Ontogenetic expression of the vanilloid receptors TRPV1 and TRPV2 in the rat retina. Int J Dev Neurosci 27:709-718. CrossRef Medline

Leonelli M, Martins DO, Britto LR (2013) Retinal cell death induced by TRPV1 activation involves NMDA signaling and upregulation of nitric oxide synthases. Cell Mol Neurobiol 33:379-392. CrossRef Medline

Liedtke W (2006) Transient receptor potential vanilloid channels functioning in transduction of osmotic stimuli. J Endocrinol 191:515-523. CrossRef Medline

Lin SY, Corey DP (2005) TRP channels in mechanosensation. Curr Opin Neurobiol 15:350-357. CrossRef Medline

Ma W, Zhang Y, Bantel C, Eisenach JC (2005) Medium and large injured dorsal root ganglion cells increase TRPV-1, accompanied by increased alpha2C-adrenoceptor co-expression and functional inhibition by clonidine. Pain 113:386-394. CrossRef Medline

Maione S, Cristino L, Migliozzi AL, Georgiou AL, Starowicz K, Salt TE, Di Marzo V (2009) TRPV1 channels control synaptic plasticity in the developing superior colliculus. J Physiol 587:2521-2535. CrossRef Medline
Marinelli S, Di Marzo V, Berretta N, Matias I, Maccarrone M, Bernardi G, Mercuri NB (2003) Presynaptic facilitation of glutamatergic synapses to dopaminergic neurons of the rat substantia nigra by endogenous stimulation of vanilloid receptors. J Neurosci 23:3136-3144. Medline

Medvedeva YV, Kim MS, Usachev YM (2008) Mechanisms of prolonged presynaptic $\mathrm{Ca}^{2+}$ signaling and glutamate release induced by TRPV1 activation in rat sensory neurons. J Neurosci 28:5295-5311. CrossRef Medline

Miller BA (2006) The role of TRP channels in oxidative stress-induced cell death. J Membr Biol 209:31-41. CrossRef Medline

Mohapatra DP, Nau C (2005) Regulation of Ca2+-dependent desensitization in the vanilloid receptor TRPV1 by calcineurin and cAMPdependent protein kinase. J Biol Chem 280:13424-13432. CrossRef Medline

Mutai H, Heller S (2003) Vertebrate and invertebrate TRPV-like mechanoreceptors. Cell Calcium 33:471-478. CrossRef Medline

Nucci C, Gasperi V, Tartaglione R, Cerulli A, Terrinoni A, Bari M, De Simone C, Agrò AF, Morrone LA, Corasaniti MT, Bagetta G, Maccarrone M (2007) Involvement of the endocannabinoid system in retinal damage after high intraocular pressure-induced ischemia in rats. Invest Ophthalmol Vis Sci 48:2997-3004. CrossRef Medline

Peters JH, McDougall SJ, Fawley JA, Smith SM, Andresen MC (2010) Primary afferent activation of thermosensitive TRPV1 triggers asynchronous glutamate release at central neurons. Neuron 65:657-669. CrossRef Medline

Pingle SC, Matta JA, Ahern GP (2007) Capsaicin receptor: TRPV1 a promiscuous TRP channel. Handb Exp Pharmacol 179:155-171. CrossRef Medline

Plant TD, Zollner C, Mousa SA, Oksche A (2006) Endothelin-1 potentiates capsaicin-induced TRPV1 currents via the endothelin A receptor. Exp Biol Med (Maywood) 231:1161-1164. Medline

Quigley HA, Broman AT (2006) The number of people with glaucoma worldwide in 2010 and 2020. Br J Ophthalmol 90:262-267. CrossRef Medline

Reilly CA, Johansen ME, Lanza DL, Lee J, Lim JO, Yost GS (2005) Calciumdependent and independent mechanisms of capsaicin receptor (TRPV1)mediated cytokine production and cell death in human bronchial epithelial cells. J Biochem Mol Toxicol 19:266-275. CrossRef Medline

Rong W, Hillsley K, Davis JB, Hicks G, Winchester WJ, Grundy D (2004) Jejunal afferent nerve sensitivity in wild-type and TRPV1 knockout mice. J Physiol 560:867-881. CrossRef Medline

Ryskamp DA, Witkovsky P, Barabas P, Huang W, Koehler C, Akimov NP, Lee SH, Chauhan S, Xing W, Rentería RC, Liedtke W, Krizaj D (2011) The polymodal ion channel transient receptor potential vanilloid 4 modulates calcium flux, spiking rate, and apoptosis of mouse retinal ganglion cells. J Neurosci 31:7089-7101. CrossRef Medline

Sappington RM, Calkins DJ (2008) Contribution of TRPV1 to microgliaderived IL-6 and NFkappaB translocation with elevated hydrostatic pressure. Invest Ophthalmol Vis Sci 49:3004-3017. CrossRef Medline

Sappington RM, Chan M, Calkins DJ (2006) Interleukin-6 protects retinal ganglion cells from pressure-induced death. Invest Ophthalmol Vis Sci 47:2932-2942. CrossRef Medline

Sappington RM, Sidorova T, Long DJ, Calkins DJ (2009) TRPV1: contribution to retinal ganglion cell apoptosis and increased intracellular $\mathrm{Ca} 2+$ with exposure to hydrostatic pressure. Invest Ophthalmol Vis Sci 50:717728. CrossRef Medline

Sappington RM, Carlson BJ, Crish SD, Calkins DJ (2010) The microbead occlusion model: a paradigm for induced ocular hypertension in rats and mice. Invest Ophthalmol Vis Sci 51:207-216. CrossRef Medline

Schumacher MA, Eilers H (2010) TRPV1 splice variants: structure and function. Front Biosci (Landmark Ed) 15:872-882. CrossRef Medline

Scotland RS, Chauhan S, Davis C, De Felipe C, Hunt S, Kabir J, Kotsonis P, Oh U, Ahluwalia A (2004) Vanilloid receptor TRPV1, sensory C-fibers, and vascular autoregulation: a novel mechanism involved in myogenic constriction. Circ Res 95:1027-1034. CrossRef Medline

Sharif-Naeini R, Ciura S, Bourque CW (2008) TRPV1 gene required for thermosensory transduction and anticipatory secretion from vasopressin neurons during hyperthermia. Neuron 58:179-185. CrossRef Medline

Siminoff R, Schwassmann HO, Kruger L (1966) An electrophysiological study of the visual projection to the superior colliculus of the rat. J Comp Neurol 127:435-444. CrossRef Medline

Stamer WD, Golightly SF, Hosohata Y, Ryan EP, Porter AC, Varga E, Noecker RJ, Felder CC, Yamamura HI (2001) Cannabinoid CB(1) receptor ex- 
pression, activation and detection of endogenous ligand in trabecular meshwork and ciliary process tissues. Eur J Pharmacol 431:277-286. CrossRef Medline

Straiker AJ, Maguire G, Mackie K, Lindsey J (1999) Localization of cannabinoid CB1 receptors in the human anterior eye and retina. Invest Ophthalmol Vis Sci 40:2442-2448. Medline

Tamayo N, Liao H, Stec MM, Wang X, Chakrabarti P, Retz D, Doherty EM, Surapaneni S, Tamir R, Bannon AW, Gavva NR, Norman MH (2008) Design and synthesis of peripherally restricted transient receptor potential vanilloid 1 (TRPV1) antagonists. J Med Chem 51:2744-2757. CrossRef Medline

Treesukosol Y, Lyall V, Heck GL, DeSimone JA, Spector AC (2007) A psychophysical and electrophysiological analysis of salt taste in Trpv1 null mice. Am J Physiol Regul Integr Comp Physiol 292:R1799-R1809. CrossRef Medline

Van Buren JJ, Bhat S, Rotello R, Pauza ME, Premkumar LS (2005) Sensitization and translocation of TRPV1 by insulin and IGF-I. Mol Pain 1:17. CrossRef Medline
Vennekens R, Menigoz A, Nilius B (2012) TRPs in the brain. Rev Physiol Biochem Pharmacol 163:27-64. CrossRef Medline

Wang X, Teng L, Li A, Ge J, Laties AM, Zhang X (2010) TRPC6 channel protects retinal ganglion cells in a rat model of retinal ischemia/reperfusion-induced cell death. Invest Ophthalmol Vis Sci 51:5751-5758. CrossRef Medline

Wanner SP, Garami A, Pakai E, Oliveira DL, Gavva NR, Coimbra CC, Romanovsky AA (2012) Aging reverses the role of the transient receptor potential vanilloid-1 channel in systemic inflammation from anti-inflammatory to proinflammatory. Cell Cycle 11:343-349. CrossRef Medline

Whitmore AV, Libby RT, John SW (2005) Glaucoma: thinking in new ways-a role for autonomous axonal self-destruction and other compartmentalised processes? Prog Retin Eye Res 24:639-662. CrossRef Medline

Xing J, Li J (2007) TRPV1 receptor mediates glutamatergic synaptic input to dorsolateral periaqueductal gray (dl-PAG) neurons. J Neurophysiol 97: 503-511. CrossRef Medline

Zhang X, Huang J, McNaughton PA (2005) NGF rapidly increases membrane expression of TRPV1 heat-gated ion channels. EMBO J 24:42114223. CrossRef Medline 